\title{
The IBAI Instrument to Assess Brand Awareness Toward Food in Children: the Chile Adaptation
}

\author{
Maria Gabriella Vecchio ${ }^{1}$, Paola Berchialla ${ }^{2}$, Nicolas Didier ${ }^{3}$, Oscar Cayul $^{3}$, Daniel Valdenegro ${ }^{3}$, \\ Marco Ghidina ${ }^{4}$, Dario Gregori, ${ }^{5, *}$ \\ ${ }^{I}$ Prochild ONLUS, Trieste, Italy \\ ${ }^{2}$ Department of Public Health, University of Turin, Turin, Italy \\ ${ }^{3}$ Sociedad Pino y Didier ltd, Santiago de Chile, Chile \\ ${ }^{4}$ Zeta Research Srl, Trieste, Italy \\ ${ }^{5}$ Unit of Biostatistics, Public Health and Epidemiology, Dept. Cardiology, Thoracic and Vascular Sciences, University \\ of Padova
}

\begin{abstract}
The prevalence of obesity and overweight in children and adolescents during the last decades has reached the epidemic level in both developed and in developing countries. Besides the genetic aspects, which represent one of the motivating factors in the progress of obesity, the shift in the energetic balance also plays a significant role in the development of obesity. TV viewing and the high-calorie snack foods consumption have come under more scrutiny as potential causes of increased obesity in children and adolescents. The aim of the present work was to develop an instrument that allows to estimate the Chilean children's brand awareness. We developed the IBAI (International Brand Awareness Instrument), an age-appropriate instrument that uses twelve sheets with pictures of food logos to test children's recall and recognition. The IBAI was presented to a sample of 80 children aged from 3 to 10 years, enrolled in the city of Santiago de Chile. The instrument allowed distinguishing different kinds of children's brand awareness. Considering the total score reached by each child, the majority of the children for both genders showed a medium-low brand awareness (32.5\%) followed by medium-high brand awareness (31.3\%), high brand awareness (23.8\%) and low brand awareness $(12.5 \%)$. Although the study confirmed the moderate brand logo recognition in the children tested, it did not demonstrate a close relationship between this and the children's reported eating behaviors, food knowledge and preferences.
\end{abstract}

Keywords: Awareness, brand, Chilean children, food logos, IBAI, nutrition.

\section{INTRODUCTION}

The prevalence of overweight and obesity in children and adolescents during the last decades has reached the epidemic level in both developed and developing countries [1]. The number of overweight children is more than 40 million worldwide [2], and obesity is associated with an increased incidence of comorbidities and the risk of premature death, resulting in a high economic impact. Obesity in children and teenagers has a negative effect on health and on the load of diseases at this stage of life, and later on in adulthood as demonstrated by researches over the last 40 years, which showed that overweight kids are at greater risk of becoming obese adults with all the health problems associated with obesity lasting through the lifespan [3]. The excess of weight would contribute to substantial increase in new cases of type 2 diabetes, coronary heart disease and stroke, hypertension, and arthritis having, consequently, a negative impact on the

*Address correspondence to this author at the Unit of Biostatistics, Public Health and Epidemiology, Dept. Cardiology, Thoracic and Vascular Sciences, University of Padova, Via Loredan, 18, 35121 Padova - Italy;

Tel: +39 049 8275384; Fax: +39 02 700445089;

E-mail: dario.gregori@unipd.it economy of a country due to health expenses and indirect costs as a result of the disease [4]. Beside the genetic aspects, which represent one of the motivating factors in the progress of obesity, the shift in the energetic balance plays a significant role in making the obesity epidemic [5]. The rapidly changing in dietary practices accompanied by an increasingly sedentary lifestyle determined the change in energetic balance, which is more oriented to the intake of kcal compared to the expenditure of energy. Television has come under more scrutiny as a potential cause of increase in obesity for children and adolescents [6] because it has been linked to the increased consumption of high-calorie snack foods [7] and to the decrease of time useful for physical activity [8] among children. The World Health Organization has recognized food marketing as an important area to focus on in the prevention of child obesity [9]. Children represent, in fact, a target easily influenced by advertising, and until now a large amount of researches has been conducted on children's ability in influencing family buying of various product categories [10]. The advertising agencies consider children as a strong opportunity to get gain because of their power and influence on family food choices and purchase. The issue of how food marketing and advertising are 
Table 1. International Brand Awareness Instrument (IBAI) -Chile



Note. List of brands and products presented in the flash cards of the IBAI with the solutions of the correct brand and the product associations.

connected to the epidemic of childhood obesity is an ongoing controversial debate. There is evidence that TV watching and food advertisements significantly influence children's behavior such as unhealthy dietary habits [11] and purchase requests for high-calorie low-nutrient products [12]. The majority of all food items advertised promotes foods mainly high in fat and/or sugar, many of which have relatively low nutritional value [13]. It is, in fact, rare to find some advertising which promotes fruit, vegetables and other healthy foods. In scientific literature, several studied on the relation between TV food advertising and the snacks' consumption in children were conducted, both on short [1316] and long-term bases [17]. A recent report by the Institute of Medicine provided a comprehensive examination of food advertising to children aged 2-11 concluding that there is strong evidence, for this class of children, that exposure to television advertising is significantly associated with adiposity [18]. Specifically, food advertisements might directly affect intake by either stimulating hunger and/or encouraging children to consume the specific foods that are marketed [19]. Branding is, in fact, a form of marketing aimed at promoting recognition with a company brand or product, in the hope that children will form emotional attachments to these products and eventually be lifelong consumers [20]. Very few instruments are however available for assessing brand knowledge and awareness in children, in particular for the age class 6-11, which is the one highly affected by food advertisements. The first one was developed for American children by Forman, Halford, Summe, MacDougall, \& Keller, which proposed a new brand awareness instrument which was basically a logomatching exercise, consisting of 30 pictures that were representative of food brand logos. Obviously, considering that some food brand logos are very common (i.e., McDonald's $($ ) while others differ in each country, this brand awareness instrument is particularly linked to the American market [21].
In Chile, from 1987 to 2000, it was observed a decline in the prevalence of under nutrition, concurrently with spiraling obesity rates both in girls and in boys [22]. Specifically in Chile, the studies on food advertising and their influence on children food choices, preferences and intake are limited. For this reason, the main aim of the present study is to develop an instrument to assess the children's brand recognition and recall suitable for the Chilean culture, the IBAI (International Brand Awareness Instrument).

\section{MATERIAL \& METHODS}

\section{Stimuli Selection}

A pool of 12 candidate items of brands was generated for the IBAI. In line with the study of Forman et al. [21], we developed the IBAI paying attention in particular to the selection of the food brands to be included. Three product categories were selected as stimuli: sweet snack, salted snack, and soft drinks. In Table 1, the complete list of brands used for the study in Santiago de Chile is presented. These foods were selected based on discussions between the investigators working on this project (in particular, between psychologists, pedagogues and nutritionists). Two main criteria were used for the accurate brand selection. First, the brands had to be available in the majority of Chilean supermarkets, smaller points of sales and other distribution channels of the area of interest of the study; second, all the brands had to belong to the category of food normally consumed by children.

In Table 2, the item response distribution for the overall IBAI results is presented.

\section{Instrument Development}

An age-appropriate instrument that used pictures of food logos to test children's recall and recognition was specifically developed. Each of the 12 logos of the selected 
Table 2. Item Response Distribution for the IBAI

\begin{tabular}{|c|c|c|c|c|c|c|}
\hline Flash Card & \multicolumn{2}{|c|}{ Brand Name } & \multicolumn{2}{|c|}{ Brand-Product Association } & \multicolumn{2}{|c|}{ Product Name } \\
\hline 2 & 78 & $98.0 \%$ & 75 & $94.0 \%$ & 75 & $94.0 \%$ \\
\hline 3 & 21 & $26.0 \%$ & 29 & $36.0 \%$ & 34 & $42.0 \%$ \\
\hline 5 & 35 & $44.0 \%$ & 37 & $46.0 \%$ & 41 & $51.0 \%$ \\
\hline 6 & 60 & $75.0 \%$ & 70 & $88.0 \%$ & 74 & $92.0 \%$ \\
\hline 7 & 64 & $80.0 \%$ & 68 & $85.0 \%$ & 67 & $84.0 \%$ \\
\hline 8 & 34 & $42.0 \%$ & 37 & $46.0 \%$ & 49 & $61.0 \%$ \\
\hline 11 & 11 & $14.0 \%$ & 14 & $18.0 \%$ & 15 & $19.0 \%$ \\
\hline 12 & 21 & $26.0 \%$ & 29 & $36.0 \%$ & 37 & $46.0 \%$ \\
\hline
\end{tabular}

brands was paired with 4 pictures of foods, and only one of them could be correctly matched with the logo. Twelve sheets for the IBAI, called flash cards, with one logo and four pictures of choices of foods (of which one was paired with the logo on the top of the sheet) were created (see Table 1 for the selected flash cards used in the IBAI). An example of one of these sheets can be found in Fig. (1).

All pictures, a total of 12 brand logos, and 48 foods ( 4 per brand logo), were laminated in $8 \times 11.5$ sheets and placed in a 3-ring binder for ease of presentation to the participating children (see [21]). The IBAI instrument is available on the website www.brand-ibai.com.

\section{Study Sample}

A total of 80 children, 40 girls and 40 boys, aged from 3 to 10 years $(\mathrm{Mean}=9.23$ years old, $\mathrm{SD}=1.83)$ participated in the study for the development of the IBAI. They were enrolled in two schools of Santiago de Chile, the Colegio Santo Domingo Savio and the Colegio Camilo Ortuzar Montt, and exposed to the study on October 2012. None of them had any known developmental delays, based on parent report. Parent informed consent was obtained for all children prior to each child's participation in the study. In order to fully explain the study to the parents of the children and reach the maximum consents, an explanatory seminar involving a certified nutritionist was conducted in both schools chosen for the study.

\section{Study Conduction}

The instrument (IBAI) was proposed to Chilean children with a recognition and a recall task. In particular, the recall task was focused on the brand naming, in line with the procedure described by Forman et al. [21] and on the product naming. We have included this last task as well, because sometimes the brand and product names are different from the actual name of the food (i.e., brand:
McDonald's@; product: Big Mac; food: hamburger). Including the product naming task, we assume that this instrument might offer a more precise and reliable measure of the children's food brand awareness.

IBAI flash cards with the image of selected brand logos were shown to each participating child individually. For each flash card every child was asked three questions in order to verify her or his knowledge about the brands and about the products associated with each of the selected brands. Every time when showing the image of the logo, the experimenter would ask "Do you know the name of this logo?" Once the child would answer whether he or she was aware of the name of the brand shown on the picture, the second question would be asked. By making a circle with the forefinger over the four pictures of different products located on the same page under the brand image, the experimenter would ask the child tow "choose the image of the food that matches with the logo". The second question was asked even if the child did not identify the brand name in the first place. That was done in order to see if the visual association with the brand image was correct without knowing the exact name. After the child would select a food picture to match, the experimenter would ask "What is the name of this product?" and would write down the exact answer of the child even if not correct. The experimenter would not tell to the children whether his or her responses were correct or not.

Each card was scored by the experimenter with 1 point if the child correctly named the logo brand, 1 point if the child chose the correct food that matched with the logo, and 1 point if the child correctly named the product. With a total of 12 flash cards, scores on the brand awareness procedure ranged from 0 to 36 ( 3 points $\times 12$ flash cards). Using this range, it was possible to create four different conventional categories of children's brand awareness: 0 -12 very low brand awareness; 13-18 medium-low brand awareness; 19-24 medium-high brand awareness; 25-36 very high brand awareness. 

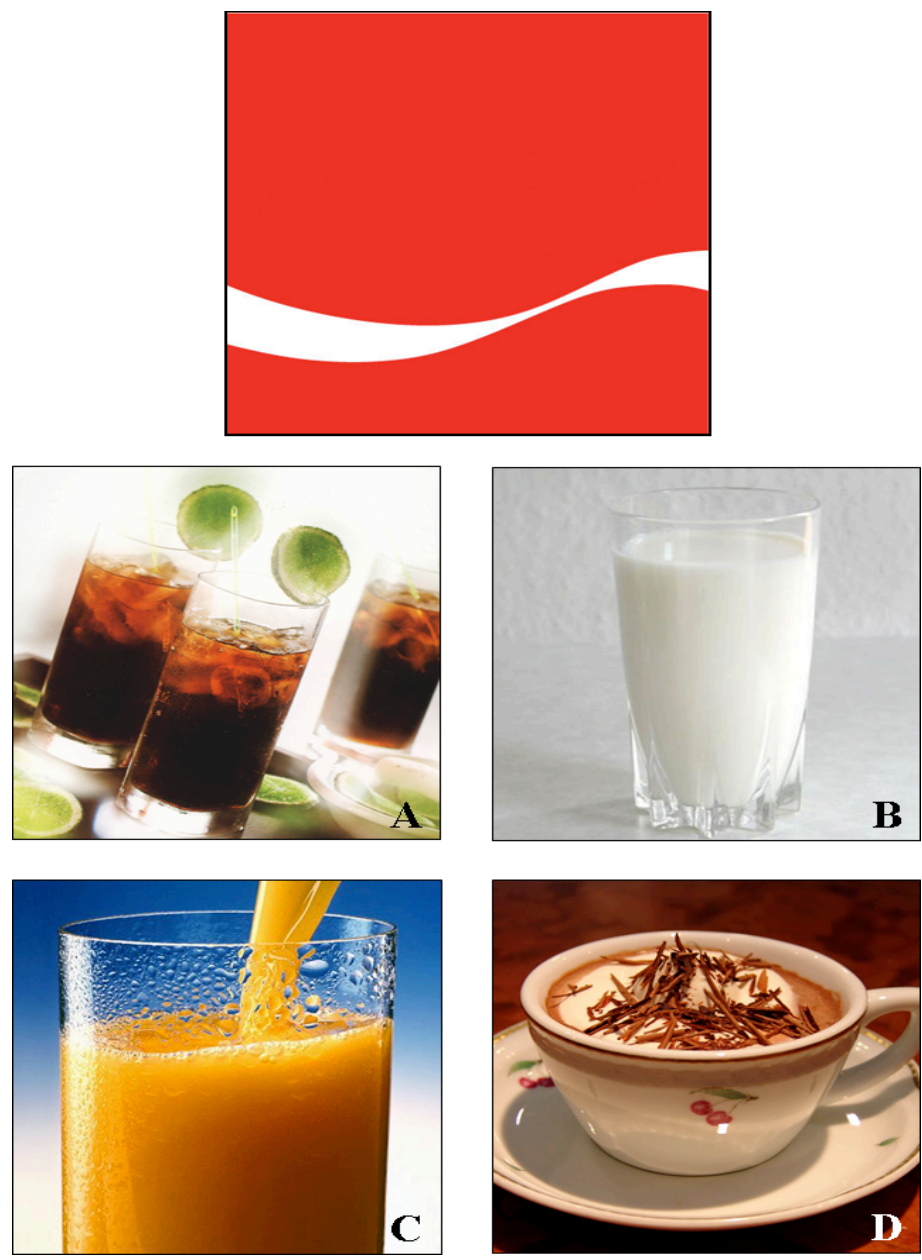

Fig. (1). An example of flash card used in the IBAI. The logo of Coca-Cola (A) was associated with milk, orange-juice and chocolate, producing a single card with five images.

Table 3. Children's total IBAI Score

\begin{tabular}{|c|c|c|c|c|c|c|c|c|c|c|}
\hline \multirow[t]{3}{*}{ IBAI Score } & \multicolumn{4}{|c|}{ Male } & \multicolumn{4}{|c|}{ Female } & \multicolumn{2}{|c|}{ Total } \\
\hline & \multicolumn{2}{|c|}{ Y3-6 } & \multicolumn{2}{|c|}{ Y7-10 } & \multicolumn{2}{|c|}{ Y3-6 } & \multicolumn{2}{|c|}{ Y7-10 } & \multirow[b]{2}{*}{$\mathbf{n}$} & \multirow[b]{2}{*}{$\%$} \\
\hline & $\mathbf{n}$ & $\%$ & $\mathbf{n}$ & $\%$ & $\mathbf{n}$ & $\%$ & $\mathbf{n}$ & $\%$ & & \\
\hline $0-12$ & 3 & $15.0 \%$ & 1 & $5.0 \%$ & 5 & $25.0 \%$ & 1 & $5.0 \%$ & 10 & $12,5 \%$ \\
\hline $13-18$ & 5 & $25.0 \%$ & 2 & $10.0 \%$ & 10 & $50.0 \%$ & 9 & $45.0 \%$ & 26 & $32,5 \%$ \\
\hline $19-24$ & 11 & $55.0 \%$ & 7 & $35.0 \%$ & 4 & $20.0 \%$ & 3 & $15.0 \%$ & 25 & $31,3 \%$ \\
\hline $25-36$ & 1 & $5.0 \%$ & 10 & $50.0 \%$ & 1 & $5.0 \%$ & 7 & $35.0 \%$ & 19 & $23,8 \%$ \\
\hline Total & 20 & $100.0 \%$ & 20 & $100.0 \%$ & 20 & $100.0 \%$ & 20 & $100.0 \%$ & 80 & $100,0 \%$ \\
\hline
\end{tabular}

\section{RESULTS}

The item response distribution (for the correct definition of the brand name, the correct association brand and product, and the correct definition of the product) for the overall IBAI is presented in Table 2. Considering the total score reached by each child, the majority of the children of both genders showed a medium-low brand awareness $(32.5 \%)$ followed by medium-high brand awareness (31.3\%), high brand awareness $(23.8 \%)$ and low brand awareness $(12.5 \%)$ (see Table 3). The results also showed that the group of children aged 3-6 demonstrated a higher brand awareness compared to the group 7-10 years, and that girls had a higher logo recognition ability compared to the boys. In order to analyze the differences in the three tasks of the IBAI (the brand naming, the brand - product association, and the product naming), statistical analysis was performed with Student's ttest for paired data. Statistical significance levels used a criterion of $p<0.05$. Comparing the number of the correct responses in the twelve items, the brand product association task presented significantly more correct responses than the brand naming task $(\mathrm{p}=0.002)$ and significantly less correct responses than the product naming task $(\mathrm{p}<0.001)$. 


\section{DISCUSSION}

The scientific interest in the last decade is focused on the increase of obesity epidemic worldwide, especially regarding the identification of the risk factors and the potential causes which lead to the increase of energy intake. For a long time, watching television has been investigated, since it replaces more vigorous activities promoting the sedentary life, and because it exposes children to a large number of important unhealthy stimuli in terms of food intake. Television was identified, in fact, as a large source of food-related information for children [23] who are exposed to poor nutritional messages in movies, shows, cartoons and advertisements that could lead to misconceptions regarding healthy nutrition [24]. In several countries worldwide, each government has already created a regulation on food marketing. In the latest forum which took place in Mexico in 2012 on the regulations regarding obesity in Latin America, one of the most relevant issues was promoting health and healthy eating habits in schools, and protecting children from being exposed to ads of packed food and sugary beverages by using effective regulatory policies. This forum was attended by experts from Brazil, Chile, Mexico, Ecuador, Perú, Argentina and Costa Rica [25]. In Europe, the directive among (and within) the countries is inconsistent. For the purposes of regulation, there was no commonly held definition of the 'child' status. Even in countries where definitions exist, there is a wide variation between 12 and 21 years. The strength of regulatory approaches ranged from very tough, as seen in Norway and Sweden where TV advertisements targeting children under 12 are banned, to the non-existent, as represented by the absence of controls in most countries [26]. In our study, we aimed to evaluate the effective role of food advertising on children choices and preferences, as well as their knowledge and awareness related to foods, especially sweet and salted snacks and soft drinks. To achieve the target, we developed an instrument which allows to estimate children brand recognition. The study shows that the IBAI form is an interesting instrument for the Chilean children's brand awareness evaluation. Following the methodology utilized by Forman et al. [21] for the development of a similar instrument utilized with American children, we developed the IBAI, specific for the Chilean culture. Considering that the children scores for the IBAI ranged in all the four created categories, we can assume that this instrument allows distinguishing different kinds of children's brand awareness. In addition, it allows to test children's recall and recognition with different tasks. In particular, the statistical analyses showed that the brandproduct association and the product naming task are easier than the brand naming, although the difference is not significant. This instrument might result very interesting in the analysis of the influence of food marketing on children's diet, considering the rapidly increasing rate of overweight children. The food promotion by the industry has a detrimental impact on children's food preferences, eating behaviors and the purchase requests they make to their parents. This issue was widely debated by several researchers who showed a strong evidence that food promotion changes or exhibits an impact on children's food propensity [27], and that child's age was positively associated with food logo recognition [28]. Our results, in the specific, showed that average children demonstrated a medium low brand awareness and that, in this group, girls presented a higher brand logo recognition ability compared to boys. This result is in accordance with Kopelman et al., who showed a significant higher brand logo recognition ability among girls, probably due to their better verbal ability and general awareness in comparison to boys [29]. Furthermore, in our study, children aged 3-6 demonstrated a higher awareness on food logos compared to the older group, highlighting younger children to be more sensitive to commercials. This result is in contrast with Forman et al. [21] which found that the recall exercise was too difficult for some children aged between 4 and 6 years, suggesting that the children age is an important factor in determining their ability to perform in the recall task. Although the study confirmed the moderate brand logo recognition in the children tested, it did not demonstrate a close relationship between this and the children's reported eating behaviors, food knowledge and preferences. Further studies to clarify the relationship between the children's advert-exposure (television viewing time) and, consequently, the brand awareness, and their weight status and their food habits are necessary. The development of instruments, such as the IBAI, specific for each country, is very important in order to study the environmental changes that have facilitated the rapid increase in childhood obesity, and the implication for the marketing of unhealthy foods to children.

\section{CONFLICT OF INTEREST}

The authors confirm that this article content has no conflicts of interest.

\section{ACKNOWLEDGEMENTS}

This research was partially funded by an unrestricted grant of the University of Padova and of Prochild ONLUS. The work has been partially supported by an unrestricted grant of the Italian Ministry of Foreign Affairs under the program "Programmi di alta rilevanza scientifica e tecnologica Italia-Messico".

\section{REFERENCES}

[1] Obesity: preventing and managing the global epidemic. Report of a WHO consultation World Health Organization technical report series 2000.

[2] Global Health Risks: mortality and burden of disease attributable to selected major risks. World Health Organization, 2009. Available from: http://www.who.int/healthinfo/global_burden_disease/global health risks/en/index.html

[3] Childhood overweight and obesity. WHO, 2010. Available from: http://www.who.int/dietphysicalactivity/childhood/en/

[4] Liria R. Consequences of obesity in children and teenagers: a problem that requires attention. Rev Peru Med Exp Salud Publica 2012; 29(3): 357-60.

[5] Qi L, Cho YA. Gene-environment interaction and obesity. Nutr Rev 2008; 66: 684-94.

[6] Hancox R, Milne B, Poulton R. Association between child and adolescent television viewing and adult health: A longitudinal birth cohort study. Lancet 2004; 364: 257-62.

[7] Coon KA, Goldberg J, Rogers BL. Relationships between use of television during meals and children's food consumption patterns. Pediatrics 2001; 107: E7

[8] Eisenmann JC, Bartee RT, MQ W. Physical activity, TV viewing, and weight in U.S. youth: 1999 Youth Risk Behavior Survey. Obes Res 2002;10: 379-85. 
[9] Marketing of food and non-alcoholic beverages to children. Report of a WHO forum and technical meeting. Oslo, Norway: World Health Organization, 2-5 May 2006.

[10] Lee CKC, Beatty SE. Family structure and influence in family decision-making. J Consume Market 2002; 19(1): 24-41.

[11] Wiecha JL, Peterson KE, Ludwig DS. When children eat what they watch. Impact of television viewing on dietary intake in youth. Arch Pediatr Adolesc Med 2006; 160: 436-42.

[12] Donkin AJ, Neale RJ, Tilston C. Children's food purchase requests. Appetite 1993; 21: 291-4.

[13] Halford JCG, Boyland MJ, Hughes G, et al. Beyond-brand effect of television (TV) food advertisement/commercials on caloric intake and food choice of 5-7-year-old children. Appetite 2007; 49: 263-7.

[14] Halford JC, Gillespie J, Brown V, et al. Effect of television advertisements for foods on food consumption in children. Appetite 2004; 42: 221-5.

[15] Epstein LH, Roemmich JN, Robinson JL. A randomized trial of the effects of reducing television viewing and computer use on body mass index in young children. JAMA Pediatr 2008; 162: 239-45.

[16] Harris JL, Pomeranz JL, Lobstein T, et al. A crisis in the marketplace: how food marketing contributes to childhood obesity and what can be done. Annu Rev Public Health 2009; 30: 211-25.

[17] Barr-Anderson DJ, Larson NI, Nelson MC, et al. Does television viewing predict dietary intake five years later in high school students and young adults? Int J Behav Nutr Phys Act 2009; 6: 7.

[18] Committee on Food Marketing and the Diets of Children and Youth. Food Marketing to Children and Youth: Threat or Opportunity? . Washington, DC: Institute of Medicine 2006.

[19] Borzekowski DLG, Robinson RN. The 30-second effect: an experiment revealing the impact of television commercials on food preferences of preschoolers. J Am Diet Assoc 2001; 101(1): 42-6.
[20] Connor SM. Food-related advertising on preschool television: building brand recognition in young viewers. Pediatrics 2006; 118 : 1478-85.

[21] Forman J, Halford JC, Summe H, et al. Food branding influences ad libitum intake differently in children dependingon weight status. Results of a pilot study. Appetite 2009; 53: 76-83.

[22] Kain J, Uauy R, Vio F, et al. Trends in overweight and obesity prevalence in Chilean children: comparison of three definitions. Eur J Clin Nutr 2002; 56: 200-4.

[23] Story M, French S. Food advertising and marketing directed at children and adolescents in the US. Int $\mathrm{J}$ Behav Nutr Phys Act 2004; 1(1): 3 .

[24] Caroli M, Argentieri L, Cardone M, et al. Role of television in childhood obesity prevention. Int J Obes 2004; 28: S104-S8.

[25] CI América Latina llama a adherir a Declaración contra la Obesidad 2013 Jan. Available from: http://es.consumersinternational.org/news-and-media/news/2013/01/ci-stgo-llamado

[26] Matthews AE. Children and obesity: a pan-European project examining the role of food marketing. Eur J Public Health 2008; 18(1): 7-11.

[27] Stoneman Z, Brody GH. Peers as mediators of television food advertisements aimed at children. Dev Psychol 1981; 17(6): 853-8.

[28] Arredondo E, Castaneda D, Elder JP, et al. Brand Name Logo Recognition of Fast Food and Healthy Food among Children. J Commun Health 2009; 34: 73-8.

[29] Kopelman CA, Roberts LM, Adab P. Advertising of food to children: is brand logo recognition related to their food knowledge, eating behaviours and food preferences? J Public Health 2007; 29(4): 358-67.

(C) Vecchio et al.; Licensee Bentham Open.

This is an open access article licensed under the terms of the Creative Commons Attribution Non-Commercial License (http://creativecommons.org/licenses/by-nc/3.0/) which permits unrestricted, non-commercial use, distribution and reproduction in any medium, provided the work is properly cited. 